\title{
Rare Bilateral Nasopalatine Duct Cysts: A Case Report
}

\author{
Marco Cicciù ${ }^{1, *}$, Giovanni Battista Grossi ${ }^{1}$, Andrea Borgonovo ${ }^{1}$, Giacomo Santoro ${ }^{1}$, Francesco \\ Pallotti $^{2}$ and Carlo Maiorana ${ }^{1}$
}

\author{
${ }^{1}$ University of Milan, Department of Oral Surgery, I.C.P. Dental School via della Commenda 10 Milan, Italy \\ ${ }^{2}$ University of Milan, Fondazione IRCCS, Ospedale Maggiore Policlinico Milan, Italy
}

\begin{abstract}
The nasopalatine duct cyst (NPDC) is the most common of the non-odontogenic cyst of the jaws. This cysts are usually central or unilateral with no prevalence of side occurrence. The NPDC is the most frequent developmental, nonodontogenic cyst of the jaws. This cyst originates from epithelial remnants from the nasopalatine duct. The cells could be activated spontaneously during life, or are eventually stimulated by the irritating action of various agents (infection, etc.). Generally, patients present without clinical signs and symptoms. Therefore, the tentative diagnosis "nasopalatine duct cyst" is often based on a coincidental radiological finding on a routine panoramic view or occlusal radiograph. The definite diagnosis should be based on clinical, radiological and above all histopathologic findings. The therapy of nasopalatine duct cysts consists of an enucleation of the cystic tissue, only in rare cases a marsupialization needs to be performed. This report describes the appearance and treatment of a rare case of bilateral nasopalatine duct cyst.
\end{abstract}

\section{INTRODUCTION}

The nasopalatine duct cyst (NPDC) is an intraosseous developmental cyst of the midline of the anterior palate. This cyst comprises about $11.6 \%$ of all jaw cysts in the maxillofacial region1 and is considered the most common nonodontogenic cyst, accounting for approximately $73 \%$ of those reported [1]. The majority of cases occur in the third to the sixth decades, and most studies show a significantly higher frequency of nasopalatine duct cysts in men that woman, the ratio being 2.5:1 [2-8]. As far as pathogenesis is concerned, it was previously thought that the NPDCs originated from the trapping of epithelium during fusion of the embryological processes [9]. This concept has been discarded, and currently NPDC is thought to develop from the epithelial remnants of the nasopalatine ducts present within the incisive canals (canals of Stenson) [3, 6, 7]. The NPDC is unique in that it develops in only one location, which is the midline of the anterior maxilla, in close relationship to the nasopalatine canal. The most common symptom is swelling, usually in the anterior region of the midline of palate. Swelling also occurs in the midline on the labial aspect of the alveolar ridge. In a number of cases, the swelling is associated with pain or drainage $[6,7,10]$. Some cysts may also be completely symptomless and be discovered by the dentist during routine radiological examination [10]. In establishing a diagnosis of NPDC it is important to attempt to exclude the possibility of a periapical lesion by testing the pulp vitality of the incisor teeth. Radiologic examination demonstrates a well-demarcated cystic structure that may appear round,

*Address correspondence to this author at the Resident of Department of Oral Surgery and Implantology, University of Milan, IRCSS, Via della Commenda 10 Milano, 20140 Italy; Tel: +390255032621;

E-mail: acromarco@yahoo.it ovoid or heart-shaped [11]. Trauma or bacterial infections have been mentioned as possible triggers, but there is very little evidence to support such hypotheses. Although aetiology of this lesion is still uncertain, the NPDC most likely represents a spontaneous cystic degeneration of remnants of the nasopalatine duct [11-13] and some genetic determinants have been suggested [14]. The microscopic features of the epithelial lining of NPDCs are highly variable, depending on the relative proximity of the nasal and oral cavities. It has been averred that cysts lined by respiratory epithelium probably originate from most superior part of the nasopalatine duct, whereas those lined by cuboidal and squamous epithelium usually originate from the lower portion of the duct, close to the oral cavity. However, the majority of cyst lining have a combination of epithelial varieties and it is not really possible to correlate position with histology. Surgical enucleation is the treatment of choice with very low recurrence rate $[5,6,15]$; however, marsupialization is an acceptable alternative in select patients [10]. Although transformation to malignancy is exceedingly rare, a single case of squamous cell carcinoma development in NDPC has been reported [16]. In this article, we describe the first reported case of bilateral nasopalatine duct cyst.

\section{CASE REPORT}

A 35-year-old, black man presented to the Oral and Maxillofacial Surgery Department of the University of Milan, I.C.P. Dental School. The patient's main complaint was swelling and elevation of the right and left nasolabial regions since 1 month. On palpation, a soft, fluctuant mass was observed which extended from the anterior buccal area up to the floor of the nose. Radiographic examination (orthopantomograph and CT scan) (Figs. 1, 2) showed two different and separated radiolucent areas in the periapical region of the upper incisors. Vitality test was positive for all anterior teeth. 


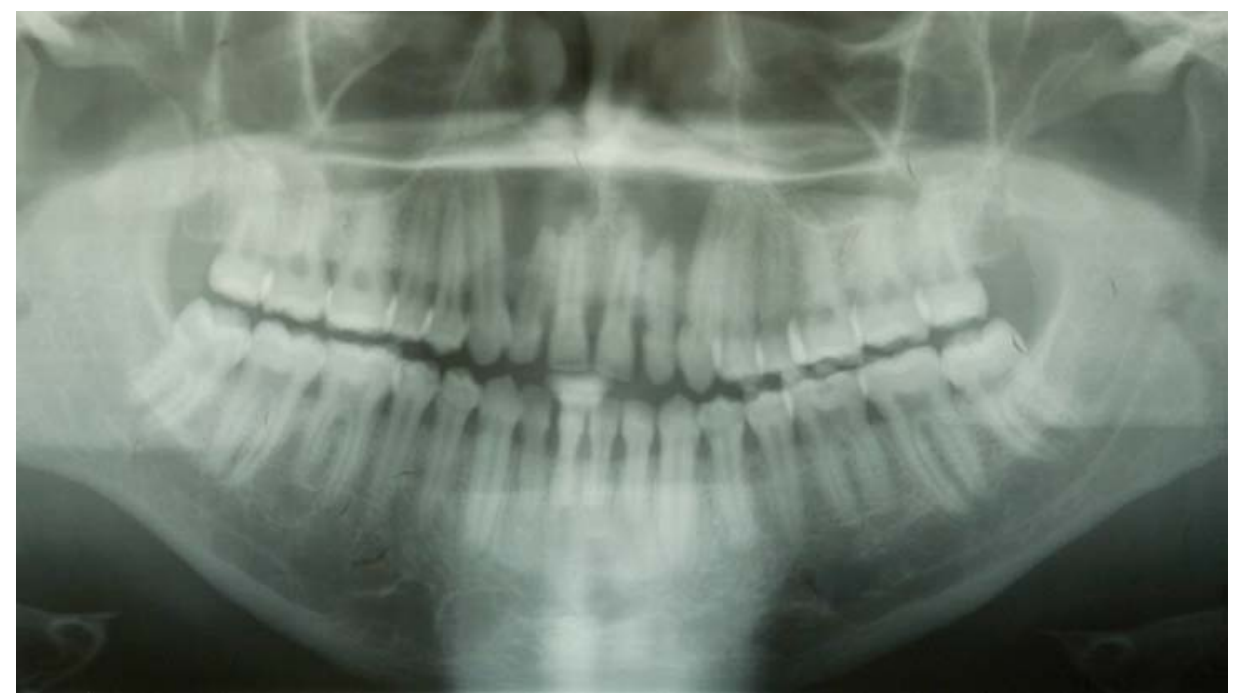

Fig. (1). Pretreatment orthopantomograph shows two different and separated cyst-like lesions between roots of maxillary anterior teeth. The lamina dura is intact although the apexes of maxilla anterior teeth appear to be in the cysts.

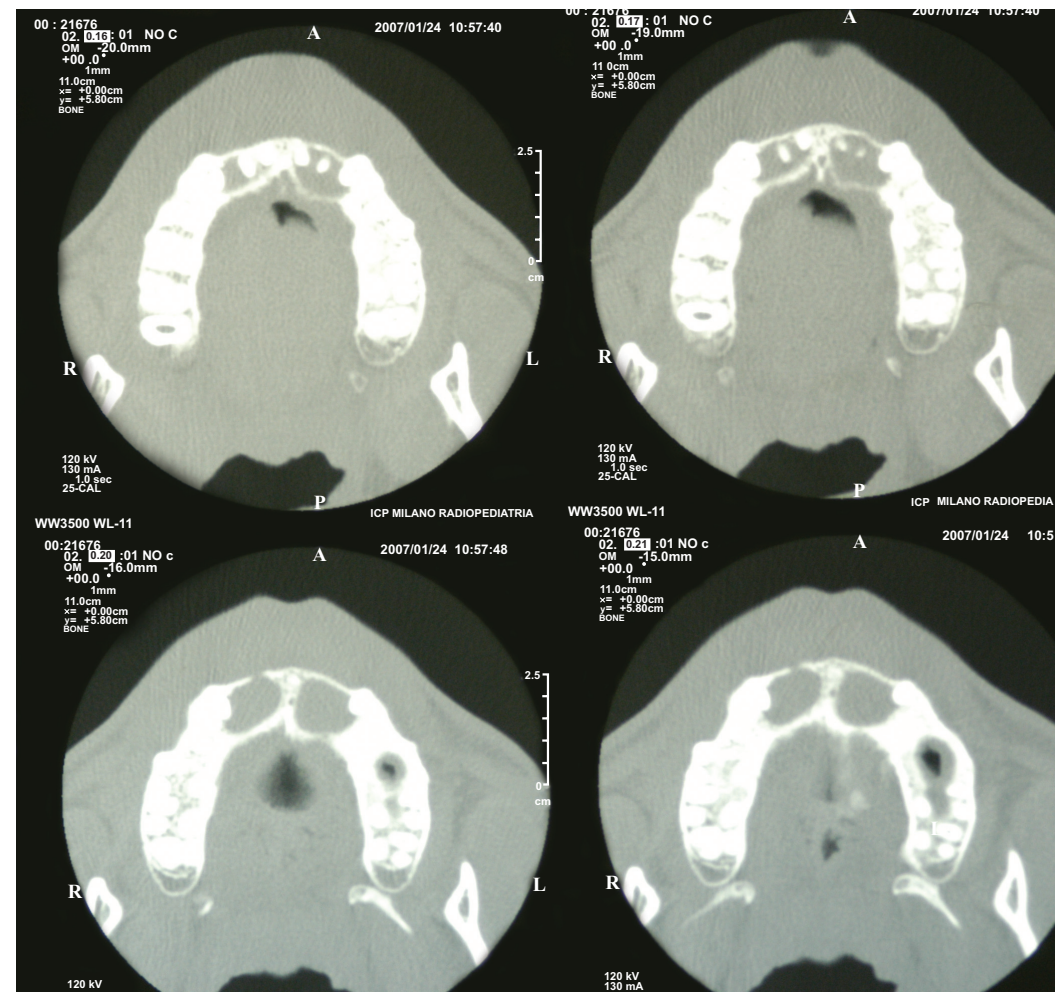

Fig. (2). CT scan demonstrating bilateral cysts.

The patient's medical history did not reveal any pathological condition. On the basis of clinical and radiographic evidence a provisional diagnosis of nasopalatine duct cyst was given. The clinical differential diagnosis included also the odontogenic keratocyst. Three weeks prior to surgery, all upper incisors received endodontic treatment by general dental practitioner, because their root apices were situated in close proximity to the cysts. The cysts were enucleated under general anaesthesia. Full thickness buccal mucoperiostal flap was raised with an intrasulcular incision. Then, the underlying cortical bone was drilled under continuous irrigation with saline solution and the lesions were removed by using sharp dissection (Figs. 3, 4). Finally, the flap was repositioned with 4-0 silk suture. Post surgical analgesic treatment was performed with $100 \mathrm{mg}$ Nimesulide ${ }^{\circledR}$ twice daily for 3 days. The patient had a soft diet for 3 days and oral hygiene instructions were provided. He was called for suture removal 10 days postoperatively and, despite some residual discomort, the tissues were healing well.

\section{HISTOPATHOLOGICAL EXAMINATION}

Macroscopically, both lesions measured approximately 8x9x8 mm, presenting a flat surface (Fig. 3). Microscopic examination revealed a fibrous wall lined by thin, nonpapil- 


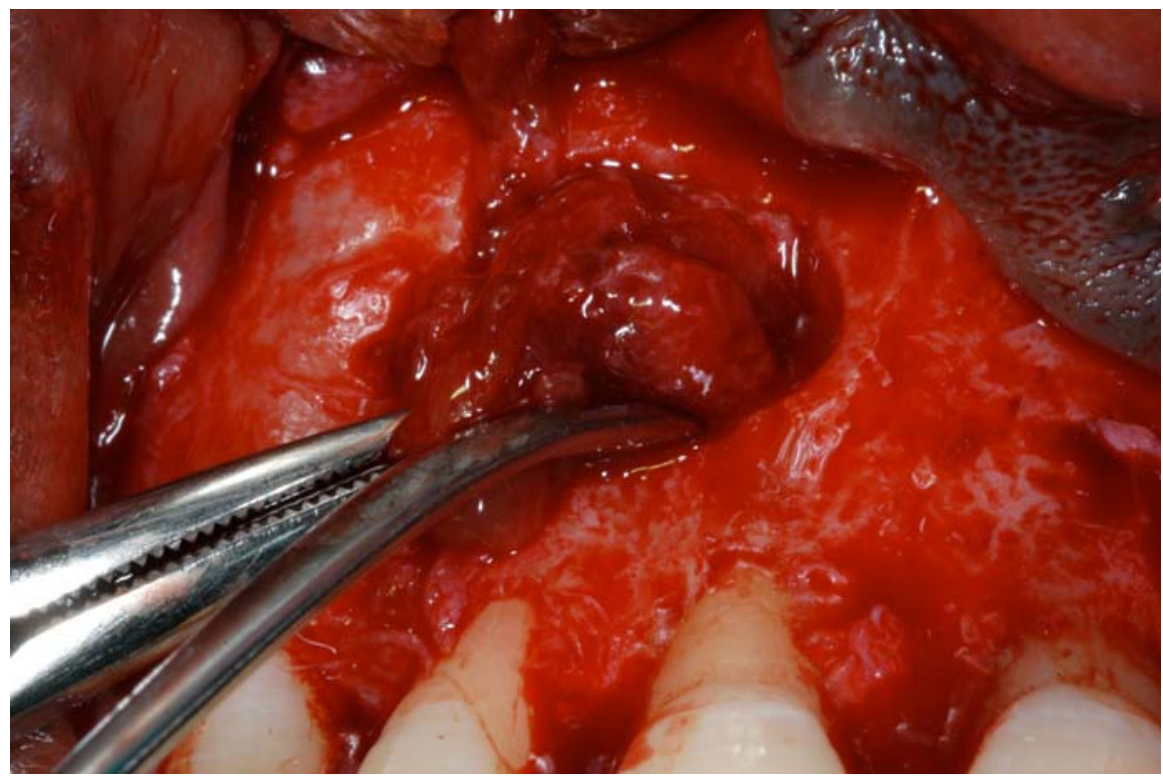

Fig. (3). The lesions were carefully separated with sharp dissection.

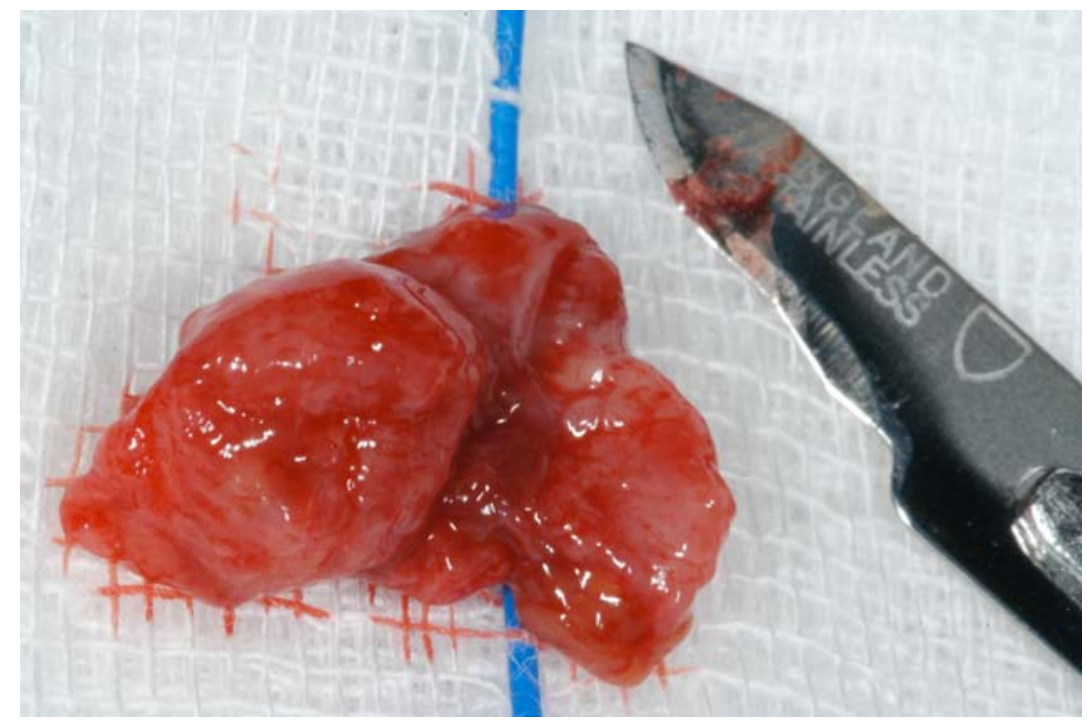

Fig. (4). Operative view of one of the cysts, removed intact.

lated cuboidal to columnar epithelium with occasional goblet cells. The cyst wall consisted of condensed fibrous connective tissue containing only scattered chronic inflammatory cells (Fig. 5).

Based on clinical, radiographic and histopathological findings a final diagnosis of nasopalatine duct cyst was arrived at. The postoperative course was uncomplicated and there was no evidence of recurrence at two years of followup (Fig. 6).

\section{DISCUSSION}

The nasopalatine duct cyst is a developmental cyst derived from proliferation of embryonic epithelial remnants of the nasopalatine duct. It may occur at any age but it is seen most often in fourth to sixth decades of life. The cause of nasopalatine duct cyst is essentially unknown. Trauma, in- fection, and mucous retention within associated salivary gland ducts have all been suggested as possible pathogenetic factors; however, most believe that spontaneous cystic degeneration of residual ductal epithelium is the most likely etiology. In the reported case there was no history of trauma, therefore it is likely for the cyst to have been caused by spontaneous development.

NPDCs are usually central or unilateral with no prevalence of side occurrence. Radiographically, some lesions may appear heart-shaped, either because they become notched by the nasal septum during their expansion or because the nasal spine is superimposed on the radiolucent area. The reported case is of particular clinical interest as it is rare for an NPDC to present bilaterally. In fact, even though it has been stated that NPDCs may occur bilaterally, in a series of 404 NPDCs identified by Shear1 only one patient 


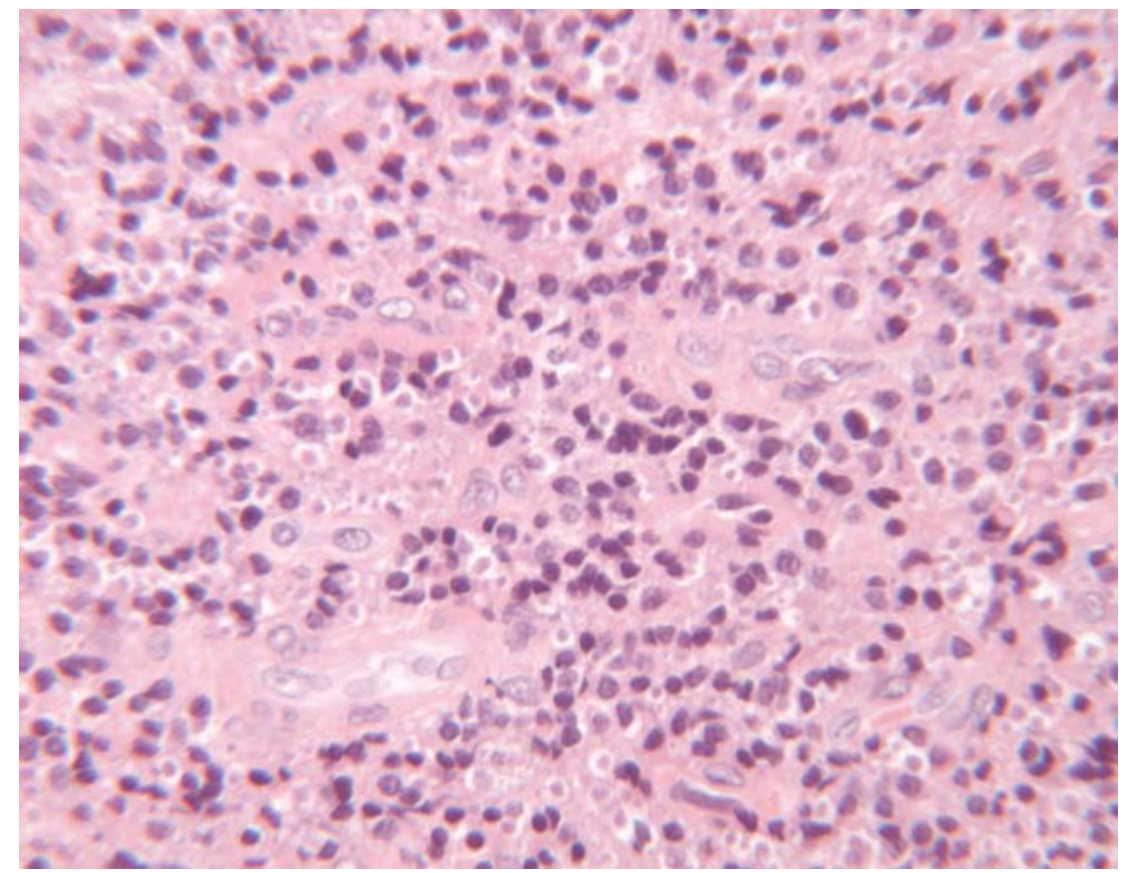

Fig. (5). Photomicrograph of nasopalatine duct cyst showing nonpapillated cuboidal to columnar epithelium with occasional goblet cells and collection of histiocytes and inflammatory cells with microhaemorrages (H\&E 4x).

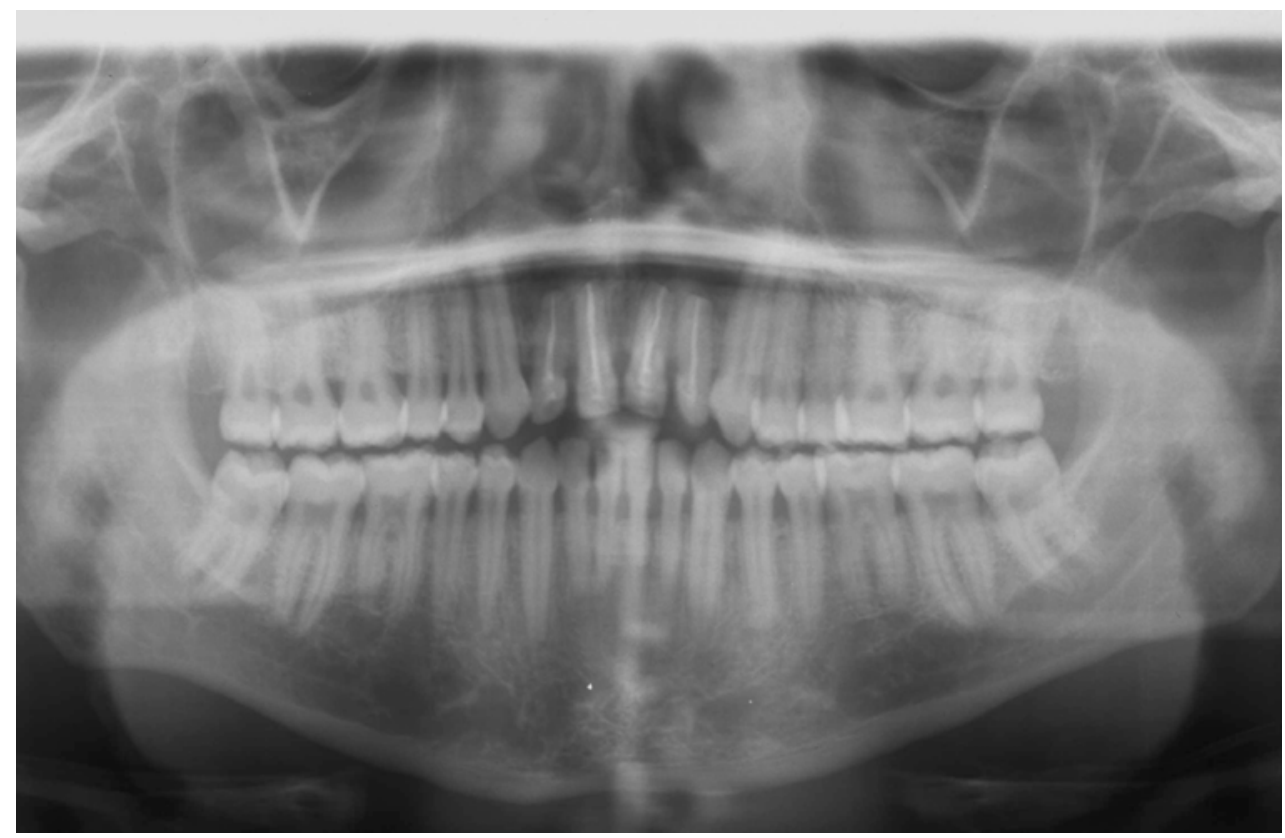

Fig. (6). Radiograph 2-years postsurgical excision shows good healing with complete bone fill evident.

developed cysts in both Stenson canals. However, to the best of our knowledge, this is the first case of bilateral NPDC documented in the English literature.

Due to similar signs and symptoms, the NPDC may be misdiagnosed as a periapical lesion. This is why many authors believe that its prevalence is actually higher than presented in the literature [17]. Although a large NPDC might show the adjacent incisors roots to be within the cystic cavity, the lamina dura will be intact and the pulp usually vital1. Whereas a radicular cyst is associated with a pulpless tooth and involve a portion of the root, usually with loss of continuity of the lamina dura. In the reported case, the lesions were close to the apexes of the maxillary anterior teeth, but all pulpal.

\section{VITALITY TESTS WERE POSITIVE.}

A reported $71.8 \%$ of nasopalatine duct cysts have squamous, columnar, cuboidal, or some combination of these epithelial types; respiratory epithelium is seen in only $9.8 \%$ $[6,18,19]$. In establishing a differential diagnosis of anterior 
radiolucencies it is important to include the odontogenic keratocyst [20]. In the patient reported here the histopathologic examination discloses a cavity lined by cuboidal and columnar epithelium surrounded by a connective tissue wall and these findings confirmed the clinical diagnosis of bilateral NPDC.

\section{CONCLUSION}

Nasopalatine duct cyst are the most common nonodontogenic cyst of the oral cavity seen in the general population. NPDCs must be distinguished from other maxillary anterior radiolucencies. Vitality testing of teeth adjacent to or involved with a cyst-like lesion is mandatory and the final diagnosis could only be performed after histological analysis. It is important that practitioners are aware of the features of the NPDC which may develop bilaterally in both Stenson canals, as shown in the present case.

\section{REFERENCES}

[1] Daley TD, Wysocki GP, Pringle GA. Relative incidence of odontogenic tumors and oral and jaw cysts in a Canadian population. Oral Surg Oral Med Oral Pathol 1994; 77(3): 276-80.

[2] Killey HC, Kay LW. An analysis of 471 benign cystic lesions of the jaws. Int Surg 1966; 46(6): 540-5

[3] Shear M, Speight PM. Cysts of the oral and maxillofacial regions. 4th ed. Oxford; Ames, Iowa: Blackwell Munksgaard 2007.

[4] Hedin M, Klamfeldt A, Persson G. Surgical treatment of nasopalatine duct cysts: a followup study. Int J Oral Surg 1978; 7(5): 427-33.

[5] Bodin I, Isacsson G, Julin P. Cysts of the nasopalatine duct. Int J Oral and Maxillofac Surg 1986; 15(6): 696-706.

[6] Swanson KS, Kaugars GE, Gunsolley JC. Nasopalatine duct cyst: an analysis of 334 cases. J Oral Maxillofac Surg 1991; 49(3): 26871 .
Allard RH, van der Kwast WA, van der Waal I. Nasopalatine duct cyst. review of the literature and report of 22 cases. Int J Oral Surg 1981; 10(6): 447-61.

[8] Elliott KA, Franzese CB, Pitman KT. Diagnosis and surgical management of nasopalatine duct cysts. Laryngoscope 2004; 114(8): 1336-40.

[9] Wiesenfield D. Cysts in the Jaw. In: Scully C, Ed. the mouth and perioral tissues. Oxford: Heinmann Medical Books 1989; p. 49-62.

[10] Vasconcelos R, de Aguiar MF, Castro W, de Araujo VC, Mesquita R. Retrospective analysis of 31 cases of nasopalatine duct cyst. Oral Diseases 1999; 5(4): 325-8.

[11] Staretz LR, Brada BJ, Schott TR. Well-defined radiolucent lesion in the maxillary anterior region. J Am Dental Associat (1939) 1990; 120(3): 335-6.

[12] Main DM. Epithelial jaw cysts: a clinicopathological reappraisal. Br J Oral Surg 1970; 8(2): 114-25.

[13] Main DM. The enlargement of epithelial jaw cysts. Odontologisk revy $1970 ; 21(1): 29-49$.

[14] Nortje CJ, Farman AG. Nasopalatine duct cyst: an aggressive condition in adolescent negroes from South Africa? Int J Oral Surg 1978; 7(2): 65-72

[15] Anneroth G, Hall G, Stuge U. Nasopalatine duct cyst. Int J Oral Maxillofac Surg 1986; 15(5): 572-80.

[16] Takagi R, Ohashi Y, Suzuki M. Squamous cell carcinoma in the maxilla probably originating from a nasopalatine duct cyst: report of case. J Oral Maxillofac Surg 1996; 54(1): 112-5.

[17] Santora E, Jr., Ballantyne AJ, Hinds EC. Nasoalveolar cyst: report of case. J Oral Surg 1970; 28(2): 117-20.

[18] Gnanasekhar JD, Walvekar SV, al-Kandari AM, al-Duwairi Y Misdiagnosis and mismanagement of a nasopalatine duct cyst and its corrective therapy: a case report. Oral Surg Oral Med Oral Pathol Oral Radiol Endod 1995; 80(4): 465-70.

[19] Abrams AM, Howell FV, Bullock WK. Nasopalatine cysts. Oral Surg Oral Med Oral Pathol 1963; 16: 306-32.

[20] Neville BW, Damm DD, Brock T. Odontogenic keratocysts of the midline maxillary region. J Oral Maxillofac Surg 1997; 55(4): 3404.

(C) Cicciù et al.; Licensee Bentham Open.

This is an open access article licensed under the terms of the Creative Commons Attribution Non-Commercial License (http://creativecommons.org/licenses/by-nc/3.0/) which permits unrestricted, non-commercial use, distribution and reproduction in any medium, provided the work is properly cited. 